\title{
A preliminary investigation of seed dispersal by elephants (Elephas maximus maximus) in Kumaragala Forest Reserve, Matale District, Sri Lanka
}

\author{
W.G.D. Chathuranga ${ }^{1,2, *}$ and K. B. Ranawana ${ }^{1}$ \\ ${ }^{I}$ Department of Zoology, Faculty of Science, University of Peradeniya, Sri Lanka \\ ${ }^{2}$ Post Graduate Institute of Science, University of Peradeniya, Peradeniya, Sri Lanka
}

Received: 23/03/2017; Accepted: 04/08/2017

\begin{abstract}
Elephants are capable of dispersing seeds in the wild and hence, have the potential to affect the vegetation dynamics of forests. Only few studies have been conducted in Sri Lanka to study the seed dispersal capability of wild elephants. Thus, this study was initiated to determine the diversity of plant species that are dispersed by the elephants in Kumaragala forest reserve, Central Sri Lanka. Dung piles were searched twice a month and three dung boli were collected randomly from each dung pile. Visible seeds were identified by comparing with a reference seed collection. A total of 84 dung piles were recorded from September 2014 to February 2015. Fifty three dung piles out of $84(63.1 \%)$ contained seeds or seedlings of one or more plant species. Most of the dung piles were found in relatively undisturbed areas of the study site. Twenty two plant species; 15 cultivated $(68.2 \%)$ and seven non-cultivated $(31.8 \%)$ plants belonging to nine families were identified from dung boli. Careya arborea, Megathyrsus maximus and Mimosa pudica were the most commonly noted seedlings. The findings of this study prove that elephants assist in dispersing seeds of some plant species in Kumaragala forest reserve area.
\end{abstract}

Keywords: Mega-herbivores, Foraging behavior, Elephant dung, Habitat enrichment, plant seeds.

\section{INTRODUCTION}

Elephants are recognized as mega-herbivores that requires enormous amounts of food every day. They consume about $1.5-2.5 \%$ of its body weight of dry forage daily (Sukumar, 2003; Mukti and Sushant, 2014). In order to obtain this large intake of food regularly, they consume variety of plants, including trees, vines, shrubs and herbs and fruiting bodies of various plant species (Samansiri and Weerakoon, 2008). Generally, the diet of Asian elephants comprises around 100 different plant species (Chen et al., 2006; Campos-Arceizet al., 2012; CamposArceiz and Blake, 2011) and their diet varies depending on the habitat type, season of the year and geographic region (Sukumar, 2003).

Twig breaking, bark peeling, branch breaking, stem twisting and pushing over are foraging behaviours of elephants (Joshi and Singh, 2008) and can directly affect the growth and survival of many herb, shrub, vine and tree species in the wild with the potential of altering the abundance and vegetation dynamics. Wasteful feeding activities of elephants such as pushing over (Joshi and Singh, 2008) can change entire ecosystems in terms of vegetation structure and composition of forests. In the meantime, elephants are also become significant seeddispersal agents (Lieberman et al., 1987; Chapman et al., 1992). Due to practical difficulties in observing fruit removal by elephants directly, the diversity of seeds dispersed by elephants is generally computed based on the contents of their dung (CamposArceiz and Blake, 2011). As elephants have large home ranges, they not only disperse seeds but also carry them far away from the parent trees. This mechanism helps to decrease higher mortality of seeds because of density-dependent factors and seed predation (Janzen, 1970). Typically, seed dispersal process facilitates to enrich and regenerate forests by changing composition and vegetation structure.

Considerable numbers of studies have been conducted to study the seed dispersal potential of African elephants (Lieberman et al., 1987; Beaune et al., 2013; Dudley, 1999; Hawthorne and Parren, 2000) and Asian elephants (Chen et al., 2006; Campos-Arceiz et al., 2012; CamposArceiz and Blake, 2011; Bhatt et al., 2011; Harich et al., 2016; Baskaran and Desai, 2013; Mukti and Sushant, 2014). These studies have 
identified and reported that elephants disperse seeds of large number of plant species.

The Sri Lankan elephant (Elephas maximus maximus) is the largest herbivorous mammal in Sri Lanka and it is considered as one of the known three subspecies of the Asian elephants. According to the Fernando et al., (2011) the current population of elephants in Sri Lanka is 5,879. Further, elephant population size of the central Sri Lanka is comparatively much lower as most of the elephants scatter in the dry zone of the country (Santiapillai et al., 2006). Kumaragala forest reserve is located in the borders between intermediate and dry zones of the central province of Sri Lanka. Therefore, population size of the elephants should be also less in this study area. Even though, considerable amount of work has been conducted to study the behavioral, feeding and nutritional ecology of elephants in Sri Lanka (Bandara and Tisdell, 2003; De Mel et al., 2013; Jayantha et al., 2009; Pastorini et al., 2010; Silva et al., 2011; Wikramanayake et al., 2006), only handful of studies have been carried out to study their seed dispersal capability in Sri Lanka (Samansiri and Weerakoon, 2008; Chathuranga et al., 2015). Therefore, the main objective of this study was to determine the diversity of plant species dispersed by elephants in Kumaragala forest reserve, Matale District, Sri Lanka.

At present, Asian elephants exist mainly in small and patchy populations because of the ever expanding agriculture and human settlements. The elephants have also been recognized as a threatened species at present. Currently, humanelephant conflict in Sri Lanka has also increased at an alarming rate and has become the major cause of elephant mortality. Thus, plant species that are dispersed by the elephants in this study area can also be affected and restricted to the other seed dispersal methods such as water, wind and other animals etc. Hence, findings of this study will also help to identify the plants that can be affected by the population reduction of elephants.

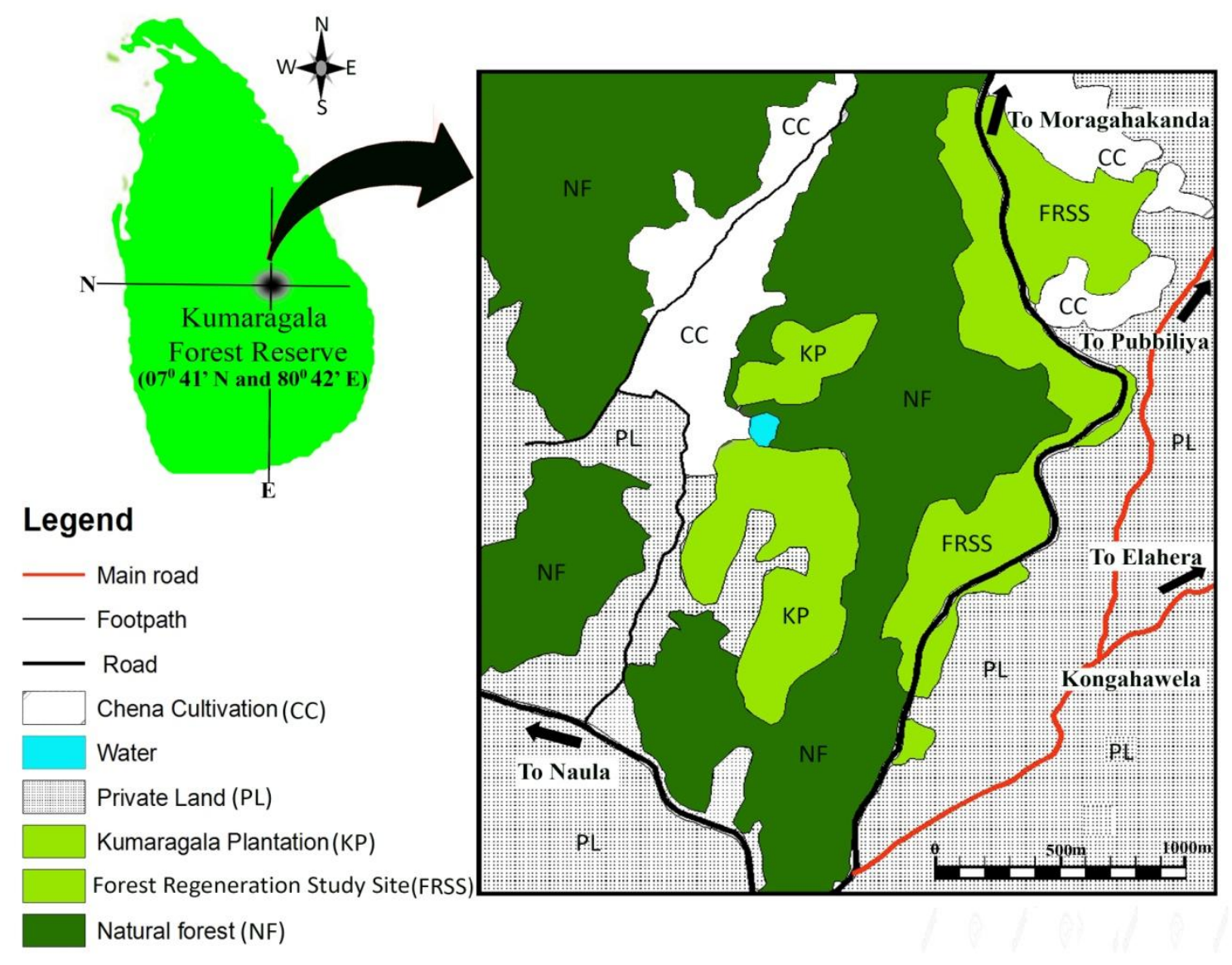

Figure 1: The Kumaragala forest reserve area showing major habitat types. 


\section{STUDY SITE}

Kumaragala Forest Reserve $\left(7^{0} 41^{\prime} \mathrm{N}-80^{\circ} 42^{\prime} \mathrm{E}\right)$ is a dry mixed evergreen forest located in the drier border of the intermediate zone of Sri Lanka. The mean annual rainfall of the area is 1750 - $2000 \mathrm{~mm}$ (De Silva et al., 2013). This area contains three major habitat types (Figure 1), namely natural forests, eucalypt plantation (FRSS and KP) and chena cultivations. The most commonly found natural vegetation type in this area is dry mixed evergreen forest with scattered deciduous trees. The natural forest that covers a part of study site is spread out $47 \mathrm{~km}$ to Habarana (De Silva et al., 2013). In early 1980s, a heavily degraded part of the Kumaragala forest reserve was leased to Ceylon Tobacco Company (CTC) to establish an Eucalyptus camaldulensis plantation to supply fuel wood for tobacco curing. After introducing an alternative sources (paddy husk) for tobacco curing, a part of the Eucalyptus plantation was harvested and was allowed to regenerate naturally. From 2006 onwards, an assisted natural regeneration (ANR) (Shono et al., 2007) method was practiced in these harvested areas (Reed et al., 2009, De Silva et al., 2013). Now, it is known as Maragamuwa Forest Regeneration Study Site (FRSS). This area supports a luxuriant growth of secondary vegetation which seems to be in a late successional stage. Three main chena cultivation areas are located in the border of natural forest and Eucalypt plantations (Figure 1).

\section{MATERIALS AND METHODS}

This study was carried out for a period of six months starting from September 2014 to February 2015. Dung piles were searched twice a month (during the first and the third weeks of the month) so as to cover natural forest, eucalypt plantation and chena (slash and burn) cultivation area. Double counting of dung piles was avoided as far as possible by taking GPS locations and marking dung piles by means of specific markers. Three boli were collected randomly from each dung pile and rest were kept in the field and observed until the decomposition was completed. Collected boli were brought to the Wildlife Research Laboratory of Department of Zoology, University of Peradeniya for further analysis. Collected dung boli were broken into small pieces and visible seeds were collected. These seeds were categorized using morphological similarities and identified by comparing with a reference seed collection which was prepared using available trees of that area. Broken boli were kept in a greenhouse and watered to identify the plants whose seeds were invisible to the naked eye. Unidentified seeds were also sown in sterilized soil and kept in the greenhouse. Later, the germinated seeds from the boli were identified using a plant guide specially prepared for Maragamuwa FRSS (Ranawana et al., 2010) and using a floral guide of Sri Lanka (Ashton et al., 1997). All environmental conditions that required for seed germination were provided throughout the study period in the greenhouse.

\section{RESULTS}

A total of 84 dung piles containing about 556 boli that dispersed in all three habitats were recorded during the study period. Of the 84 dung piles, $55(65.5 \%)$ were recorded in the natural forest area. Twenty (23.8\%) and nine (10.7\%) dung piles were found from chena cultivations and Eucalypt plantations, respectively. Fifty three piles (Natural forest-36; Chena area-12 and Eucalypt plantation-5) out of 84 (63.09\%) contained seeds or seedlings of one or more plant species. A total of 22 plant species belonging to nine families were germinated from dung boli. Cucurbitaceae, Fabaceae and Poaceae were the most frequently noted plant families (Table 1 and Table 2). Among the 22 plant species, 15 species (68.2\%) were cultivated crops (Table 1). Seven (31.8\%) were non-cultivated plant species (Table 2).

It is interesting to note that 17 plant species were identified in the chena cultivation area. Of these, 12 plant species $(70.6 \%)$ belonged to cultivated plants. Furthermore, nine and eight plant species were identified from natural forest and Eucalypt plantation areas, respectively (Table 1 and Table 2). Megathyrsus maximus, Careya arborea and Mimosa pudica were the most frequently identified seeds and seedlings from all three habitats. Specially, Megathyrsus maximus was the most abundant seedling type in all three habitats and those seedlings were too numerous to count. Careya arborea was the second most common seedling type of noncultivated plant species (Figure 2A) and Cucumis melo was the most common seedling type that belongs to cultivated plants (Figure 2B). 
Table 1: List of cultivated plant seeds which were dispersed by the elephants in the study area.

\begin{tabular}{|c|c|c|c|c|c|c|}
\hline \multirow{2}{*}{ Family } & \multirow{2}{*}{ Species } & \multirow{2}{*}{ Life form } & \multirow{2}{*}{ English name } & \multicolumn{3}{|c|}{ Habitat } \\
\hline & & & & NF & $\mathbf{E P}$ & $\mathrm{CC}$ \\
\hline Amaranthaceae & Amaranthus lividis & Herb & Red Amaranth & - & - & + \\
\hline Moraceae & Artocarpus heterophyllus & Tree & Jackfruit & + & + & $=$ \\
\hline Anacardiaceae & Mangifera indica & Tree & Mango & - & + & - \\
\hline \multirow[t]{5}{*}{ Cucurbitaceae } & Cucumis melo & Climber & Melon & + & - & + \\
\hline & Cucurbita maxima & Climber & Pumpkin & - & - & + \\
\hline & Benincasa hispida & Climber & Winter melon & + & - & + \\
\hline & Eleusine coracana & Herb & Finger millet & - & - & + \\
\hline & Zea mays & Herb & Maize & + & - & + \\
\hline \multirow[t]{2}{*}{ Solanaceae } & Capsicum annum & Herb & Chili Pepper & - & - & + \\
\hline & Solanum melongena & Herb & Brinjal & - & - & + \\
\hline \multirow[t]{4}{*}{ Fabaceae } & Vigna unguiculata & Climber & Yard long bean & - & - & + \\
\hline & Phaseolus vulgaris & Herb & Bean & - & - & + \\
\hline & Vigna marina & Climber & Beach pea & - & - & + \\
\hline & Tamarindus indica & Tree & Tamarind & - & + & - \\
\hline Poaceae & Oryza sativa & Herb & Asian rice & + & - & + \\
\hline
\end{tabular}

Habitat: NF-Natural Forest; EP-Eucalypt Plantation; CC-Chena Cultivations

Table 2: List of non-cultivated plant seeds which were dispersed by the elephants in the study area.

\begin{tabular}{lllllll}
\hline \multirow{2}{*}{ Family } & \multicolumn{1}{c}{ Species } & Lifeform & English name & NF & EP & CC \\
\cline { 5 - 6 } Lecythidaceae & Careya arborea & Tree & Patana oak & + & + & + \\
Fabaceae & Bauhinia racemosa & Tree & Maila & + & - & - \\
& Mimosa pudica & Herb & Touch-me-not & + & + & + \\
Poaceae & Panicum curviflorum & Herb & Vietnamese & - & + & + \\
& Megathyrsus maximus & Herb & Green Panic Grass & + & + & + \\
& Eleusine indica & Herb & Crow foot Grass & - & - & + \\
Rutaceae & Limonia acidissima & Tree & Wood Apple & + & + & - \\
\hline
\end{tabular}
Habitat: NF-Natural Forest; EP-Eucalypt Plantation; CC-Chena Cultivations
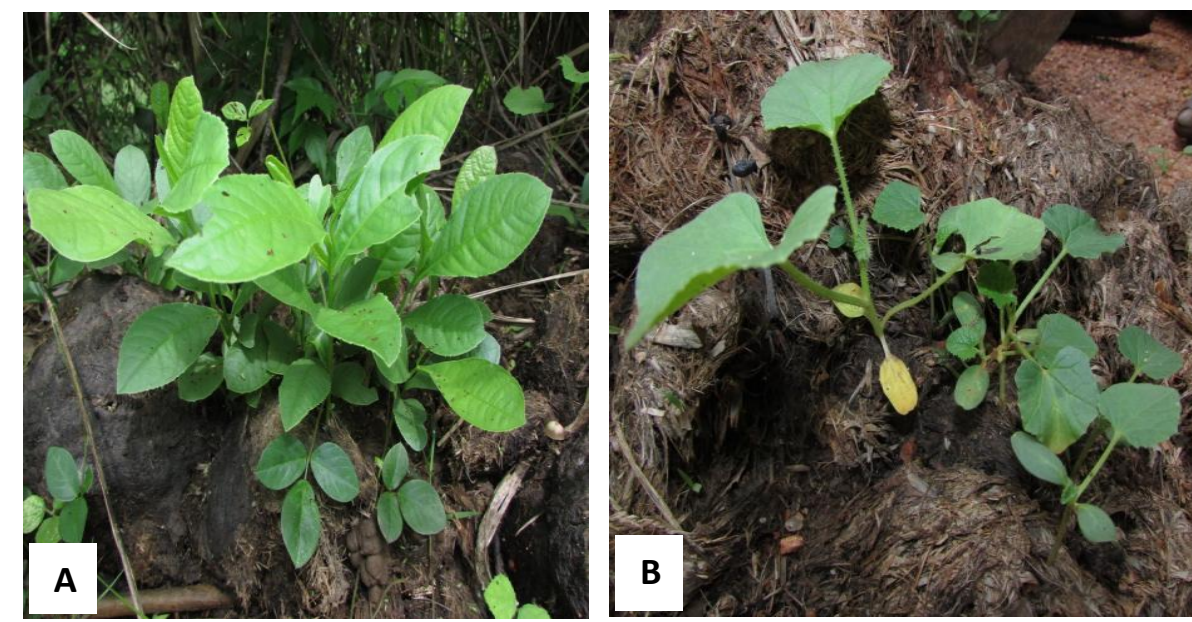

Figure 2: Germination of Careya arborea (A) and Cucumis melo (B) from elephant dung piles. 


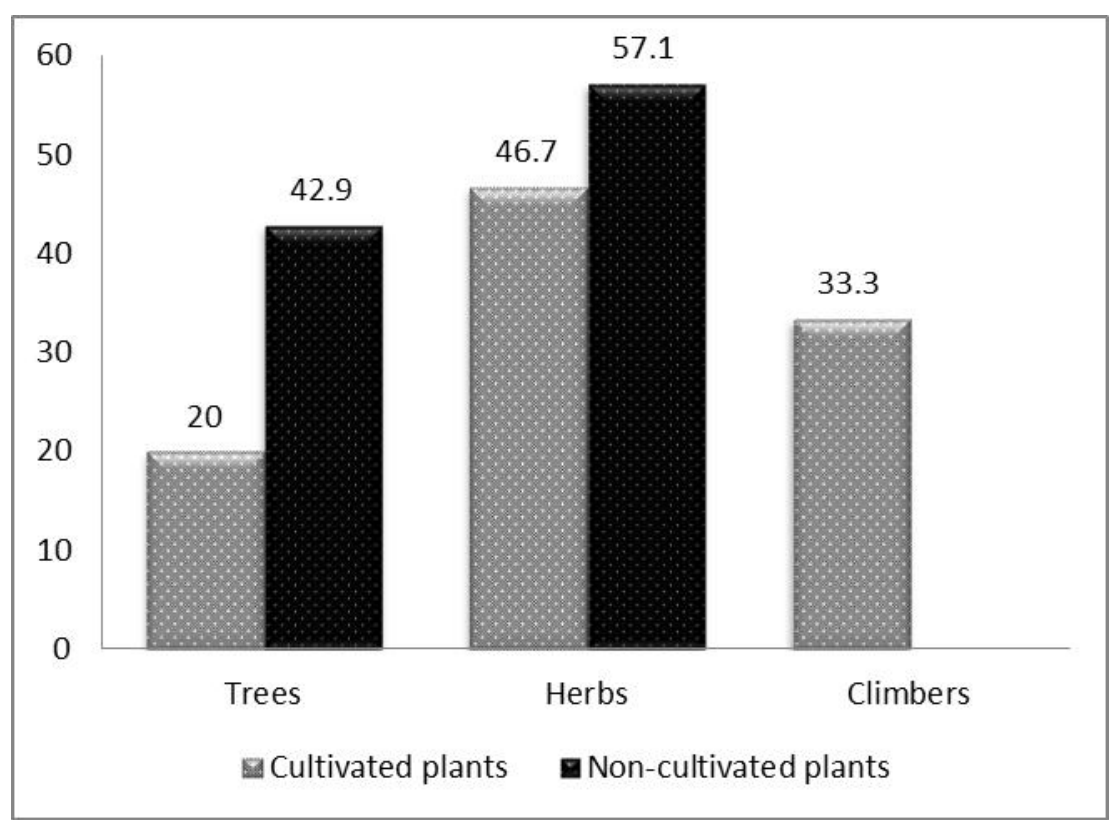

Figure 3: Life forms of plants which were identified from elephant dung piles.

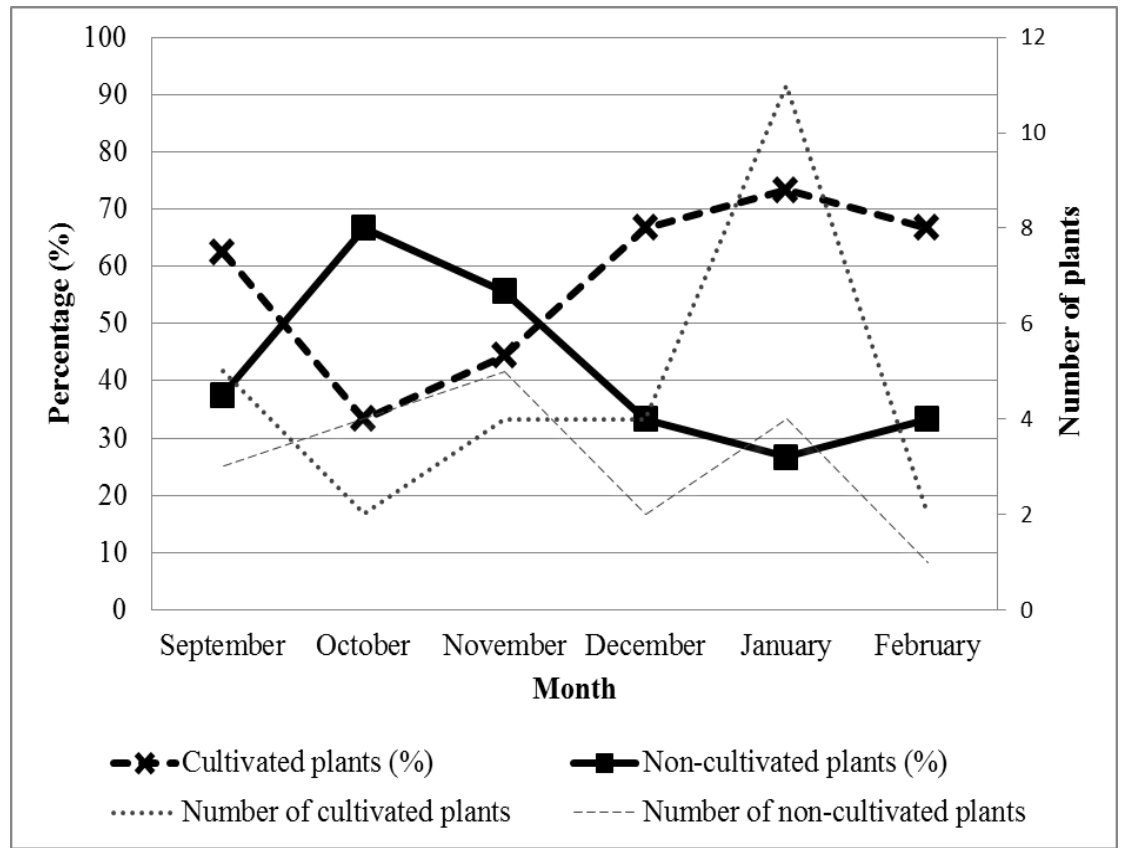

Figure 4: Percentage and number of cultivated and non-cultivated plants which were recorded from dung piles.

Herbs were the most regularly documented life form of both cultivated (46.7\%) and noncultivated (57.1\%) plants (Figure 3). Comparatively, higher percentages of cultivated plants were recorded from December to February (Figure 4) and it coincides with the fruiting season and harvesting period of the chena cultivations in the study area. It is noteworthy to highlight that the distribution of non-cultivated plants reduces during the harvesting period. The highest number of plant species (15 plants) was recorded in January including 11 cultivated plant species while only three were recorded in February (Figure 4).

\section{DISCUSSION}

In total, seeds and seedlings that belong to 22 plant species were recognized in elephant dung. Among them, 17 plant species were recorded from chena cultivation area. Of these, 12 species were identified as cultivated plants, indicating their dependence on crops from the chena 
cultivations during both cultivated and noncultivated periods. According to the results of this study, elephants have shown a higher tendency to enter into chena cultivations during the fruiting season. This is the time plants showing the highest potential to get their seeds dispersed by animals including elephants. Once farmers harvest their crops, a considerable amount of plants with fruits remain in the field, and as a result elephants tend to come to chena cultivations even after the crop is been harvested.

Most of the time, the availability of seeds in dung boli coincides with the fruiting season of wild trees and the cultivation patterns of chenas. The cropping season of chena cultivation in the area is mainly from mid-October to end of February in the following year. This study has also been initiated to coincide with the beginning of the chena cultivation and the data has been collected for a period of six months. The seeds of cultivated plants recorded in this study have been increased both at the beginning of the fruiting season and the end of the harvesting period.

Megathyrsus maximus was the most common non-cultivated plant species while Cucumis melo was the most common cultivated plant recorded in this study. Megathyrsus maximus grow well in abandoned chena cultivation areas and in gaps in the natural forests and eucalypt plantations. This plant has been reported in all study sites, and seems to be the preferred food source by elephants. Cucumis melo are not only planted in chenas but also in home gardens. Thus, these two plants are available for elephants throughout the year.

Water acts as one of the major limiting factors for seed germination in elephant dung boli (Samansiri and Weerakoon, 2008). In this study, all dung piles were collected during a dry period, hence if this study carried out during a rainy season, the results may be different. According to the Sukumar (2003), the diet of elephants varies depending on the habitat type, geographic region and especially with season of the year. Therefore, it is better to continue this study for a longer period to get a proper idea about seed dispersal potential of elephants and to understand about the seasonal variations of the diet of elephants in this area.

According to villagers and farmers living in the vicinity of the Kumaragala forest reserve, the elephants that live in this area spend their day time in the natural forest and come to chena cultivations and Eucalypt plantations during the night time. The present study has located 55 dung piles out of the total of $84(65.5 \%)$ from the natural forest. This is a relatively high number compared to other habitats in the study. These findings further proved the observations of villagers and farmers. The elephants seem to spend reasonably more time in natural forest than other two habitats, chenas and eucalypt plantations.

According to Campos-Arceiz and Blake (2011) African elephants in forests disperse seeds more than African savannah and Asian elephants. African forest elephants disperse 451 species, from 268 genera in 73 families. Further, they highlighted that elephants found in areas closer to the equator tend to disperse seeds with high diversity due to availability of high plant diversity, animal mediated seed dispersal and larger seed size. However, Asian elephants are also known to disperse 122 species from 92 genera in 39 families (Campos-Arceiz and Blake, 2011). Comparatively, present study noted less number of plants (22 plant species from 21 genera in nine families). Even though the numbers are small, the present findings can provide important information regarding the diversity of plant species that are dispersed by Sri Lankan elephants.

Samansiri and Weerakoon (2008) have studied the seed dispersal capability of elephants in the north western region of Sri Lanka and identified 34 plant species including 20 noncultivated and 14 cultivated plants. Seven noncultivated plants and 10 cultivated plants which were documented by Samansiri and Weerakoon (2008) have also been reported in the present study. Even though, the two studies have been carried out in two different areas of the country, the results showed some similarities of plants those seeds dispersed by elephants. The seed dispersal capability of elephants in the central of Sri Lanka is still unknown. As the present study is focussed on central part of the country, this information will be useful in identifying conservation measures for elephants in the central of Sri Lanka.

At present, the Asian elephants exist in small and patchy populations because of rapid habitat destruction, and alteration, deforestation, expanding agriculture and human settlements (Santiapillai et al., 2006). The Human-Elephant 
Conflict (HEC) in Sri Lanka has been increasing at an alarming rate and has become the foremost reason for elephant mortality. Furthermore, the elephants have been recognized as a threatened species at present (Santiapillai et al., 2006). To address some of these problems, the present findings can be used to develop habitat enrichment programs for wild elephants. Further, it will help to mitigate the HEC, which has become a serious conservation issue for elephants in Sri Lanka.

\section{CONCLUSION}

Elephants act as seed dispersal agents for both cultivated and non-cultivated plant species in Kumaragala forest reserve area. More than $65 \%$ of the elephant dung piles contain one or more seeds or seedlings indicating their significant role as seed dispersers. The results also suggest that the elephants spend more time in natural forests than other habitats in the Kumaragala forest reserve area.

\section{ACKNOWLEDGEMENTS}

The first author is grateful to Mr. Chaminda Wijesundara and Mr. Danula Jayasingha for their field assistance and the research assistants Messrs. Sanjeewa Jayarathna and Sanjaya Karunarathne of Wildlife Research Laboratory, Department of Zoology, University of Peradeniya for their encouragement and support at the laboratory.

\section{REFERENCES}

Ashton, M.S., Gunatilleke, S., De Zoysa, N., Dassanayaka, M.D., Gunatilleke, N. and Wijesundara, S. (1997). A field guide to the common Trees and Shrubs of Sri Lanka. WHT publications, Colombo, Sri Lanka. Pp.430.

Bandara, R. and Tisdell, C. (2003). Comparison of rural and urban attitudes to the conservation of Asian elephants in Sri Lanka: Empirical evidence. Biological Conservation 110(3): 327342. $\quad$ http://doi.org/10.1016/S0006-3207 (02)00241-0

Barnes, R.F.W. (1996). The conflict between humans and elephants in the central African forests. Mammal Review 26 (2-3): 67-80.

Baskaran, N and Desai, A. D. (2013). Frugivory and seed dispersal by the Asian Elephant Elephas maximus in the tropical forests of Nilgiri Biosphere Reserve, southern India. Journal of Threatened Taxa 5(14): 4893-4897.

Beaune, D., Bretagnolle, F., Bollache, L., Hohmann, G., Surbeck, M. and Fruth, B. (2013). Seed dispersal strategies and the threat of defaunation in a Congo forest. Biodiversity and Conservation 22(1): 225-238. http://doi.org/10.1007/s10531012-0416-x

Bhatt, P., Pradhan, N. M. B. and Wegge, P. (2011). Seed dispersal by megaherbivores: do Asian elephants disperse Mallotus philippinensis, a main food tree in northern India and Nepal?. Journal of Natural History 45 (15-16): 915-921. http://doi.org/10.1080/00222933.2010.538088

Campos-Arceiz, A. and Blake, S. (2011). Megagardeners of the forest - the role of elephants in seed dispersal. Acta Oecologica 37 (6): 542-553. doi:10.1016/j.actao.2011.01.014.

Campos-Arceiz, A., Traeholt, C., Jaffar, R., Santamaria, L. and Corlett, R. T. (2012). Asian Tapirs Are No Elephants When It Comes To Seed Dispersal. Biotropica 44 (2): 220-227. http://doi.org/10.1111/j.1744-7429.2011.00784.x

Chapman, L.J., Chapman, C.A. and Wrangham, R.W., 1992. Balanites wilsoniana -elephant dependent dispersal. Journal of Tropical Ecology 8: 275283.

Chathuranga, D., Ranawana, K. B., Wijesundara, C. S. and Jayasinghe, D. (2015). Seed dispersal potential of Asian elephants (Elephas maximus) in Kumaragala Forest Reserve, Matale District, Sri Lanka. International Forestry and Environment Symposium 2015: 23.

Chen, J., Deng, X.B., Zhang, L. and Bai, Z. (2006). Diet composition and foraging ecology of Asian elephants in Shangyong, Xishuangbanna, China. Acta Ecol Sin 26 (2):309-316. doi: 10.1016/S1872-2032(06)60006-1.

de Mel, R. K., Weerakoon, D. K. and Ratnasooriya, W. D. (2013). A comparison of stereotypic behaviour in asian elephants at three different institutions in Sri Lanka. Gajah 38: 25-29.

de Silva, T., Ranawana, K.B., Fernando, S. and Ellepola, G. (2013). Comparison of Avifaunal Composition in a Natural and Regenerated Forest; Towards using Birds as Ecological Indicators. Ceylon Journal of Science (Biological Sciences) $\quad \mathbf{4 2}(2)$ : $\quad 71-78$. DOI:http://doi.org/10.4038/cjsbs.v42i2.6610

Dudley, J. P. (1999). Seed dispersal of Acacia erioloba by African bush elephants in Hwange National Park, Zimbabwe. African Journal of Ecology $37(4)$ : $375-385$. http://doi.org/10.1046/j.1365-2028.1999.00191.x

Fernando, P., Jayewardene, J. Prasad, T., Hendavitharana, W. and Pastorini, J. (2011). Current Status of Asian Elephants in Sri Lanka.Gajah 35: 93-103.

Harich, F. K., Treydte, A. C., Ogutu, J. O., Roberts, J. E., Savini, C., Bauer, J. M. and Savini, T. (2016a). Seed dispersal potential of Asian elephants. Acta Oecologica 77: 144-151. http://doi.org/10.1016/j.actao.2016.10.005

Hawthorne, W. D. and Parren, M. P. E. (2000). How important are forest elephants to the survival of 
woody plant species in Upper Guinean forests?. Journal of Tropical Ecology 16(1), 133-150. http://doi.org/10.1017/S0266467400001310

Janzen, D. H. (1970). Herbivores and number of tree species in tropical forest. American Naturalist 104: 504-528.

Jayantha, D., Dayawansa, P. N., Padmalal, U. K. G. K., and Ratnasooriya, W. D. (2009). Social relationships of wild juvenile Asian Elephants Elephas maximus in the Udawalawa National Park, Sri Lanka. Journal of Threatened Taxa 1: 211-214.

http://doi.org/10.11609/JoTT.o1831.211-4

Johnsingh, A. J. T. and Williams, A. C. (1999). Elephant corridors in India: lessons for other elephant range countries. Oryx 33:210-214.

Joshi, R. and Singh, R. (2008). Feeding behaviour of wild Asian Elephants (Elephas maximus) in the Rajaji National Park. The Journal of American Science 4(2): 34-48.

Lieberman, D., Lieberman, M. and Martin, C. (1987). Notes on the seeds in the elephant dung from Bia National Park. Biotropica 19: 365-369.

Mukti.R and Sushant.C. (2014).Foraging Ecology of the Asian Elephant in Northern West Bengal.Gajah 40:18-25.

Pastorini, J., Nishantha, H. G., Janaka, H. K., Isler, K. I. and Fernando, P. (2010). Water-body use by Asian elephants in Southern Sri Lanka. Tropical Conservation Science3(4): 412-422.

Ranawana, K.B., Alahakoon, A.M.D.B., Nanayakkara, A. and Ekanayaka, D. (2010). Guide to common plants in Ceylon tobacco company biodiversity site, Maragamuwa. Ceylon Tobacco Company PLC press: Pp.38.

Reed, T., Ranawana, K. B and Nanayakkara, A. (2009). Methods tested and their costs to control regrowth of coppiced Eucalyptus camaldulensis in harvested plantations in Naula, Matale District, Sri Lanka. Ceylon Journal of Science (Bio Science) 38 (2): $75-83$.

Samansiri, K. A. P. and Weerakoon, D. K. (2008). A Study on the Seed Dispersal Capability of Asian Elephants in the Northwestern Region of Sri Lanka. Bauhinia 28: 19-24.

Santiapillai, C., Fernando, P. and Gunewardene, M. (2006). A strategy for the conservation of the Asian elephant in Sri Lanka. Gajah 25: 91-102.

Shono, K., Cadaweng, E.A., and Durst, P.B. (2007). Application of Assisted Natural Regeneration to restore degraded tropical forestlands. Restoration Ecology 15 (4): 620-626.

Silva, S. de, Ranjeewa, A. D. G. and Weerakoon, D. (2011). Demography of Asian elephants (Elephas maximus) at Uda Walawe National Park, Sri Lanka based on identified individuals. Biological Conservation 144(5): 1742-1752. http://doi.org/10.1016/j.biocon.2011.03.011
Sukumar, R. (2003). The Living Elephants: Evolutionary Ecology, Behaviour and Conservation. Oxford University Press, New York. Pp. 1-478.

Wikramanayake, E., Fernando, P., and Leimgruber, P. (2006). Behavioral response of satellitecollared elephants to the tsunami in southern Sri Lanka. Biotropica 38(6): 775-777. http://doi.org/10.1111/j.1744-7429.2006.00199.x 